\title{
Normative beliefs about breaking road safety rules and their relation to risk-taking
}

\author{
Anna Olejniczak-Serowiec ${ }^{1}{ }^{*}$, and Dorota Rutkowska ${ }^{1}$ \\ ${ }^{1}$ University of Warsaw, Faculty of Psychology, Stawki 5/7, 00-183 Warsaw, Poland
}

\begin{abstract}
Normative beliefs are proved to correlate significantly with behavioural intentions and behaviour [1-3], also driving behaviour [4,5]. This means, that normative beliefs about road safety might be directly related to driving behaviour. On the other hand, many research demonstrate that driving behaviour is well correlated with risk-taking. However, risk-taking and dealing with uncertainty is not a homogenous construct. As Blais and Weber argue, our proneness to take risk depends on the decision domain [6]. According to the authors, vehicle driving falls into the domain of health and safety. If so, normative beliefs about breaking legal road safety rules should correlate with risk-taking in the domain of health and safety. The aim of the study was to verify whether normative beliefs about breaking road safety rules are related to risk-taking, especially in the domain of health and safety. An online study on Polish drivers $(\mathrm{N}=180 ; 114$ female and 66 male $)$ aged $19-81(\mathrm{M}=33, \mathrm{SD}=$ 12.25) was conducted. Normative beliefs about breaking road safety rules were measured with the Controversies questionnaire [pol. Kontrowersje] [7] - an originally developed 10 item scale based on Polish traffic regulations. Proneness to take risk was measured with Polish version of the DOSPERT (Domain Specific Risk-taking) questionnaire [6]. The questionnaire consists of 30 items divided into six scales which represent risk-taking behaviour in six domains: social, recreational, financial/investment, financial/gambling, health/safety, and ethical risk. The results of the study confirmed that normative beliefs about breaking traffic safety rules are correlated with risk-taking in general. There is also a statistically significant correlation between the score in Controversies scale and risk-taking in the domain of health and safety. The strength of this correlation, however, is not age-independent. Even more interestingly, age groups differ with regard to the domain in which risk-taking correlates with drivers' normative beliefs which lead to the acceptance of breaking the traffic rules. While for the oldest subjects the correlation has been observed in the domain of health/safety specifically, in the youngest group it occurred in most of the domains, but the highest coefficients have been obtained for financial risk-taking. The results of the study need further examination due to the limited number of the older participants. However, the results suggest initially that vehicle driving might fall into different domains of risky decision making for various groups of individuals. Consequently, it might be useful to differentiate social communication intended to promote safe driving, so that it could refer to various domains of life.
\end{abstract}

\footnotetext{
* Corresponding author: anna.olejniczak@psych.uw.edu.pl
} 


\section{Introduction}

Human error is pointed out to be the major cause of $90-95 \%$ of road accidents, and drivers are considered to be the main perpetrators [8]. As drivers are considered the main actors in road safety, it seems crucial to understand their behaviour and the source of their errors. Among different kinds of errors, an important part of driving behaviour results from following road safety rules [9], which emphasizes the meaning of the drivers attitude towards legal and social norms. Its importance is further enhanced by the Polish Ministry of Health regulation, which requires transportation psychologist to verify drivers' norms understanding [10]. Norms understanding encompasses not only knowing them and being aware of the consequences of neglecting them, but also getting its sense in relation to one's individual values system [11]. Legal and social norms incorporated into, and deeply rooted in the individual's system of values, may express themselves as normative beliefs.

Normative beliefs are defined as internal standards describing which behaviours are or are not acceptable in a given situation[12], or what an individual imagines that important others expect him or her to do in a certain situation [1]. The standards make basis for evaluation of individual behaviour norms, which are reflected in behavioural intentions and observed behaviour [1,2]. Such subjective norms seem to be a good explanation of behavior [13]. Research proove normative beliefs to be signifantly related to a range of behaviours: aggression [12,14] and helping others [14], as well as risky driving [4] and traffic safety rules violating [5]. This means, that normative beliefs about road safety might be directly related to driving behaviour.

On the other hand, many research demonstrate that driving behaviour is well correlated with risk-taking, risk-perception, and risk-acceptance $[15,16]$. However, risk-taking and dealing with uncertainty is not a homogenous construct. According to Blais and Weber [6], the preference for risk-taking vs. risk-avoiding differs depending on the domain of life to which the risk reffers. This means, that a person who tends to seek risk in one domain of life, may be risk-avoidant in another. The authors identified five domains, in which preference for risk-taking may be observed:

a) Social Risk - encompasess behaviours which may provoke social tensions (e.g., disagreeing with a widely accepted authority);

b) Recreational Risk - encompasess potentially dangerous but exciting entertainments (e.g., parachuting);

c) Financial Risk - encompasess risky business decisions (e.g., investment in new business) and hazard (e.g., betting at horse races);

d) Helth/Safety Risk - expresses in low care for one's health (e.g., unprotected sex);

e) Ethical Risk - encompasess behaviours contrary to widely accepted moral rules (e.g., having a romance with a married person).

As both normative beliefs and risk-taking are related to driving behavior, it may be assumed, that they are also correlated with each other. Risky vehicle driving is associated with risk-taking in the domain of health and safety [6]. If so, normative beliefs which lie beneath the acceptance of violating the legal safety rules should also correlate with risktaking in the domain of health and safety. An exploratory study was designed, to check whether people of different age differ with regard to the relation between their normative beliefs about breaking traffic safety rules and the domain in which risk-taking may occur. 


\section{Method}

\subsection{Participants and procedure}

An online study was conducted. A sample consisted of 180 (114 female and 66 male) anonymous Polish volunteers aged 19-81 $(\mathrm{M}=33, \mathrm{SD}=12.25)$. Due to the missing data, the analyses were performed on the sample of 174 drivers (111 female included). All of them were active driving licence holders.

Each of the participants answered demographic questions, which were followed by the Controversies questionnaire and the DOSPERT questionnaire.

\subsection{Materials}

Normative beliefs were measured with 10-item questionnaire called Controversies, which was developed by the authors [7]. The questionnaire is based on the Polish highway code. Each item addresses violation of a chosen rule from the code. The participant's task is to answer on a 5 point Likert scale, to what extent each behaviour is permissible ( 1 - definitely not permissible, 5 - definitely permissible). The higher the score, the more permissive the beliefs about breaking legal road safety rules.

The DOSPERT scale [6] consists of 30 items, which describe risky activities and fall into one of five sub-scales. Each sub-scale addresses risk-taking in a certain domain: social, recreational, financial, health and safety, and ethics. Risk-taking in the financial domain is further divided into gambling and investments. The participants are asked to answer, how likely they are to behave in accordance with the description provided with each item. The answers are marked on a 7 point scale $(1-$ Extremely unlikely, 7 - Extremely likely). The score on each scale is counted as a mean answer to the items included in the scale. Apart from that, a general DOSPERT score, which covers risk-taking propensity in all of the domains, is counted. The higher the scores, the more likely the participant is to take risk in a given domain or in general.

\section{Results}

The sample was divided into four age groups based on the major life changes (e.g., graduating from the university or letting children out of family home and retirement) based on statistical data and developmental theories $[17,18]$. The oldest group was excluded from most of the analyses, as the number of participants in this group was too small.

Table 1. Descriptive statistics of the distinguished age groups.

\begin{tabular}{|c|c|c|c|c|c|}
\hline Age group & $\boldsymbol{N}$ & Minimum age & Maximum age & $\boldsymbol{M}$ & $\boldsymbol{S D}$ \\
\hline 1 & 45 & 19 & 25 & 21.37 & 2.10 \\
\hline 2 & 95 & 26 & 40 & 30.93 & 4.17 \\
\hline 3 & 27 & 41 & 58 & 48.83 & 5.16 \\
\hline 4 & 7 & 64 & 81 & 86.63 & 5.34 \\
\hline Total & 174 & 19 & 81 & 33 & 12.25 \\
\hline
\end{tabular}

\subsection{Correlation between normative beliefs and risk-taking}

The results of Pearson correlation analyses confirmed that in all age groups normative beliefs which lie beneath the approval of breaking traffic safety rules are positively correlated with risk-taking in the domain of health and safety. In the first age group, it was 
also positively correlated with recreational, financial, and ethical risk-taking. In the second age group the correlation of normative beliefs and risk-taking in the domain of health and safety was accompanied by positive correlation with social, financial, recreational, and ethical risky behaviour. In the third age group health and safety, recreational, financial, and ethical risk-taking were positively correlated with the score in Controversies questionnaire. Pearson coefficients are presented in table 2.

Table 2. Pearson correlation coefficients between Controversies scale and risk-taking scores.

\begin{tabular}{|c|c|c|c|c|c|c|c|}
\hline \multirow{2}{*}{$\begin{array}{c}\text { Age } \\
\text { group }\end{array}$} & \multirow{2}{*}{$\begin{array}{c}\text { General } \\
\text { risk- } \\
\text { taking }\end{array}$} & \multirow{2}{*}{$\begin{array}{c}\text { Social } \\
\text { risk }\end{array}$} & \multirow{2}{*}{$\begin{array}{c}\text { Recreatio } \\
\text { nal risk }\end{array}$} & \multicolumn{2}{|c|}{ Financial risk } & \multirow{2}{*}{$\begin{array}{c}\text { Health/safet } \\
\text { y risk }\end{array}$} & \multirow{2}{*}{$\begin{array}{c}\text { Ethical } \\
\text { risk }\end{array}$} \\
\hline & & & & Gambling & Investment & & \\
\hline \multirow{2}{*}{1} & \multirow{2}{*}{$.56^{* * *}$} & \multirow{2}{*}{.21} & \multirow{2}{*}{$.32 *$} & \multicolumn{2}{|c|}{$55 * * *$} & \multirow{2}{*}{$.32 *$} & \multirow{2}{*}{$.26^{*}$} \\
\hline & & & & $.57 * * *$ & $30 *$ & & \\
\hline \multirow{2}{*}{2} & \multirow{2}{*}{$.44^{* * *}$} & \multirow{2}{*}{$.21^{*}$} & \multirow{2}{*}{$.29 * *$} & \multicolumn{2}{|c|}{$21 *$} & \multirow{2}{*}{$.49 * * *$} & \multirow{2}{*}{$.56^{* * *}$} \\
\hline & & & & .13 & $.25 * *$ & & \\
\hline \multirow{2}{*}{3} & \multirow{2}{*}{$.50 * *$} & \multirow{2}{*}{.04} & \multirow{2}{*}{$.53 * *$} & & ** & \multirow{2}{*}{$.39^{*}$} & \multirow{2}{*}{$.44 *$} \\
\hline & & & & .30 & $.60 * * *$ & & \\
\hline
\end{tabular}

${ }^{*} p<0.05,{ }^{* *} p<0.01,{ }^{* * *} p \leq 0.001$ one tailed.

As the number of oldest participants was too small to provide reliable analyses $(n=7)$ they were excluded from the following considerations. Nonetheless, an interesting correlation was observed in this group: permissive normative beliefs about breaking traffic rules were significantly correlated with risk-taking only in one domain - health and safety $(r=0.84, p=0.01)$.

The scores for risk-taking in various domains were also significantly inter-correlated (table 3).

Table 3. Pearson inter-correlations matrix.

\begin{tabular}{|c|c|c|c|c|c|c|c|}
\hline $\begin{array}{c}\text { Age } \\
\text { group }\end{array}$ & & SR & RR & GFR & IFR & HSR & ER \\
\hline \multirow{6}{*}{1} & SR & 1 & .27 & .03 & .28 & -.07 & .14 \\
\cline { 2 - 8 } & RR & .27 & 1 & $.43^{*}$ & $.38^{*}$ & $.35^{*}$ & .21 \\
\cline { 2 - 8 } & GFR & .03 & $.43^{*}$ & 1 & $.32^{*}$ & .18 & $.33^{*}$ \\
\cline { 2 - 8 } & IFR & .28 & $.38^{*}$ & $.32^{*}$ & 1 & .17 & .18 \\
\cline { 2 - 8 } & HSR & -.07 & $.35^{*}$ & .18 & .17 & 1 & $.44^{*}$ \\
\cline { 2 - 8 } & ER & .14 & .21 & $.33^{*}$ & .18 & $.44^{*}$ & 1 \\
\hline \multirow{6}{*}{2} & SR & 1 & $.54^{*}$ & $.23^{*}$ & $.29^{*}$ & $.50^{*}$ & $.31^{*}$ \\
\cline { 2 - 8 } & RR & $.54^{*}$ & 1 & .16 & $.29^{*}$ & $.56^{*}$ & $.35^{*}$ \\
\cline { 2 - 8 } & GFR & $.23^{*}$ & .16 & 1 & $.68^{*}$ & $.30^{*}$ & $.35^{*}$ \\
\cline { 2 - 8 } & IFR & $.29^{*}$ & $.29^{*}$ & $.68^{*}$ & 1 & $.43^{*}$ & $.28^{*}$ \\
\cline { 2 - 8 } & HSR & $.50^{*}$ & $.56^{*}$ & $.30^{*}$ & $.43^{*}$ & 1 & $.61^{*}$ \\
\cline { 2 - 8 } & ER & $.31^{*}$ & $.35^{*}$ & $.35^{*}$ & $.28^{*}$ & $.61^{*}$ & .24 \\
\hline \multirow{6}{*}{3} & SR & 1 & $.41^{*}$ & .20 & .30 & .24 & .22 \\
\cline { 2 - 8 } & RR & $.41^{*}$ & 1 & $.53^{*}$ & $.71^{*}$ & $.63^{*}$ & $.49^{*}$ \\
\cline { 2 - 8 } & GFR & .20 & $.53^{*}$ & 1 & $.71^{*}$ & $.49^{*}$ & $.66^{*}$ \\
\cline { 2 - 8 } & IFR & .30 & $.71^{*}$ & $.71^{*}$ & 1 & $.68^{*}$ & .62 \\
\cline { 2 - 8 } & HSR & .24 & $.63^{*}$ & $.49^{*}$ & $.68^{*}$ & 1 & .61 \\
\cline { 2 - 8 } & ER & .22 & $.48^{*}$ & $.56^{*}$ & .62 & .61 & 1 \\
\hline
\end{tabular}

$* p<0.05$

SR - Social Risk, RR - Recreational Risk, GFR - Gambling Financial Risk,

IFR - Investment Financial Risk, HSR - Health/Safety Risk, ER - Ethical Risk 


\subsection{Comparisons of correlation coefficients}

To verify whether risk-taking in any particular domain is associated with permissive normative beliefs about breaking road safety rules, a series of within age groups comparisons was performed. The results of these comparisons are presented in table 4.

Table 4. Significance level of differences in the correlation coefficients within age groups.

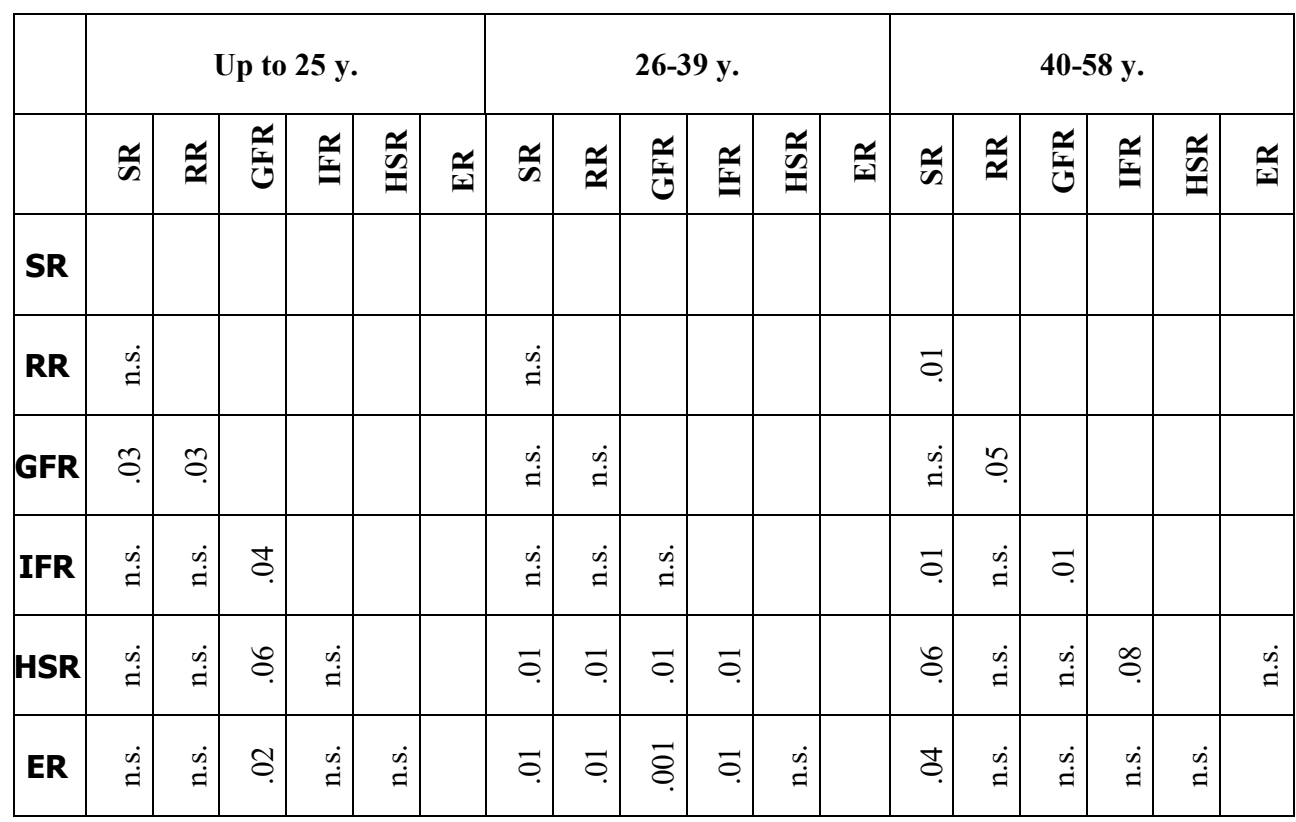

SR - Social Risk, RR - Recreational Risk, GFR - Gambling Financial Risk, IFR - Investment

Financial Risk, HSR - Health/Safety Risk, ER - Ethical Risk

The within group correlation coefficients comparisons revealed that normative beliefs about braking traffic-safety rules correlate with risk-taking in the domain of financial gambling more strongly than with risk-taking in any other domain. The correlation, however, loses its' strength in older groups, becoming less significant than the correlation with risk-taking in the domain of financial gambling. In the second age group risk-taking in the domains of ethics and in the domain of health and safety are stronger than with risktaking in any other domain. In the third age group, we observed the weakest correlation with social risk-taking, although there is no significant difference when compared with risktaking in the domain of financial gambling. The later was also less correlated with permissive normative beliefs about braking road safety rules than risk-taking in the domain of recreation. Correlation of the other subscale of financial risk-taking - investments was stronger than that of risk-taking in the domain health and safety.

Furthermore, comparisons of correlation coefficients between age groups were performed to verify whether they differ with regard to the domain in which risky behaviour correlates with permissive normative beliefs about breaking road safety rules. Significant differences were revealed between the youngest group and the second age group, i.e. permissive normative beliefs were more strongly correlated with risk-taking in the domain of financial gambling $(\mathrm{p}=0.01)$ in the youngest group than in the second age group. The two groups differed also in the level of correlation with ethical risk-taking, i.e., the correlation was stronger in the second age group than in the first $(p=0.05)$. We also obtained the difference between the second and the third age group in the strength of correlation with risk-taking in the domain of financial investment $(\mathrm{p}=0.05)$, i.e., the 
correlation was significantly stronger in the third age group. It was also marginally $(\mathrm{p}=$ $0.11)$ stronger than in the youngest group. Additionally, a statistical trend $(p=0.08)$, indicating that correlation with recreational risk-taking was stronger in the third age group than in the second was observed.

\section{Discussion}

The results of the study confirmed that normative beliefs about breaking traffic safety rules are correlated with risk taking in general. There is also a statistically significant correlation between the scores in Controversies questionnaire and risk taking in the domain of health and safety, and the age groups of drivers do not differ significantly with respect to the coefficients.

The results of the study show that, across life span, permissive normative beliefs are also consequently correlated with risky behaviours in the domains of ethics, recreation, and finance. However, in the domain of risky financial behaviour the relation with propensity for gambling is gradually replaced with propensity for risky investment. This might be related to the decrease of the overall propensity to take any financial risk in older adults [19], although this particular finding may result from the life circumstances and socioeconomic status of an individual: those who are likely to take risk in the investment domain, are also willing to take the risk of the expenses that may follow violating traffic rules.

In the group of very young (under 25) drivers, normative beliefs which lead to the acceptance of breaking traffic rules is quite strongly correlated with the propensity to take risk in financial gambling domain. The relation, however, disappears with age. Research focusing on the relation between domain specific risk taking and Sensation Seeking Scale [20] show that propensity to take risk in the domain of financial gambling is positively correlated with Experience seeking and Disinhibition, while it is not related to Thrill and adventure seeking. In such a case, permissive normative beliefs about breaking road-safety rules in young drivers may express looking for new experiences, making use of newlygained skills, and general new state which is being adult and independent, while being relatively not connected with looking for the so called adrenaline boost in risky driving. It should be noted that in that group the correlation between normative beliefs and risky behaviour in the domain of ethics is not particularly strong which may indicate that most young drivers do not violate road safety rules due to the weak internal ethical standards.

The relation between normative beliefs about breaking traffic rules and seeking for behaviours which are risky in terms of social ethics seems to be stronger in drivers between 26 th and 40th year of age. For this age group violating road safety rules may result from neglecting other social ethics to a greater extent than in case of younger drivers. This may indicate that, in drivers at this age, breaking traffic rules may result from low level of responsibility for oneself and others, and weak understanding of primary moral and ethical rules, which suggests not fully achieved social maturity.

Drivers in the 41-58 age group are more likely to hold normative beliefs which lie beneath violating traffic rules when they seek for risk in all of the domains apart from social and gambling risky behaviours. However, it should be noted that in that group the correlation between normative beliefs and recreational, as well as investment risk, is stronger than in younger adults, which may indicate that in those drivers violating traffic rules may be an expression of engaging in dangerous, adventurous activities and being eager to make risky business decisions.

The observed correlations with social risk taking are weak and non-consequent, which might mean that car driving is not perceived as a social situation. Such perception may, in turn, result in increasing the number of socially unaccepted traffic behaviours. 
Subsequently, efforts directed towards increasing the awareness of the social component in vehicle driving might be beneficial for road safety by decreasing the frequency of countersafety rule breaking behaviour.

The results of the study need further examination due to the limited number of older participants. However, the results suggest initially that rule breaking vehicle driving might fall into different domains of risky behaviour for various groups of individuals depending on their age. Consequently, it might be useful to differentiate social communication intended to promote safe driving, so that it could refer to various domains of life. Numerus differences between various groups in the observed relations between permissive normative beliefs about breaking traffic rules and domain specific risk taking also suggest that it might be useful to distinguish similar groups of drivers in the studies on risk taking and rule breaking behaviours.

The study was founded by the Faculty of Psychology, University of Warsaw funds DSM $114211 / 2016$.

Authors would like to express their gratitude to Michał Białek and Lukasz Markiewicz for kindly sharing the unpublished Polish version of the DOSPERT questionnaire.

\section{References}

1. I. Ajzen, M. Fishbein, Attitudinal and normative variables as predictors of drinking behavior, J. Pers. Soc. Psychol. 27 pp. 41-57 (1973). doi: $10.1177 / 0022002187018003003$

2. M.F. Icek Ajzen, Robert L. Heilbroner, Understanding Attitudes and Predicting Social Behavior (Englewood Cliffs, NJ: Prentice-Hall, 1980)

3. M. Fishbein, I. Ajzen, Belief, Attitude, Intention, and Behavior: An Introduction to Theory and Research (Reading, MA: Addison-Wesley, 1975)

4. G. Adamos, E. Nathanail, Predicting the effectiveness of road safety campaigns through alternative research designs, J. Safety Res. 59 pp. 83-95 (2016). doi:10.1016/j.jsr.2016.10.003

5. D. Parker, A. Manstead, S. Reason, J. Baxter, Intention To Commit Driving Violations: An Application of the Theory of Planned Behaviour, J. Appl. Psychol. 77 (1992)

6. E.U. Weber, A.-R. Blais, A Domain-Specific Risk-Taking ( DOSPERT ) scale for adult populations, Judgement Decis. Mak. 1 pp. 33-47 (2006). doi:10.1037/t13084000

7. A. Olejniczak-Serowiec, D. Rutkowska, Kwestionariusz do badania przekonań normatywnych kierowców dotyczących łamania prawa o ruchu drogowym, Transp. Samoch. 3 pp. 37-53 (2017)

8. Road accidents in Poland in 2015 (General Police Headquarters of Poland, Warsaw, 2016)

9. J. Reason, Human Error (Cambridge University Press, Cambridge, 1990)

10. Rozporządzenie Ministra Zdrowia z dnia 8 lipca 2014 r. w sprawie badań psychologicznych osób ubiegających się o uprawnienia do kierowania pojazdami, kierowców, DZ. U. z 2014, poz. 937. (2014)

11. A. Tarnowski, System Test2Drive w badaniach psychologicznych kierowców, Transp. Samoch. 2 pp. 83-96 (2014)

12. L.R. Huesmann, N.G. Guerra, Children's Normative Beliefs About Aggression and 
Aggressive Behavior, Personal. Soc. Psychol. 72 pp. 408-419 (1997)

13. J. Cestac, S. Kraïem, J.P. Assailly, Cultural values and random breath tests as moderators of the social influence on drunk driving in 15 countries, J. Safety Res. 56 pp. 89-96 (2016). doi:10.1016/j.jsr.2015.12.001

14. H. Machackova, J. Pfetsch, Bystanders' responses to offline bullying and cyberbullying: The role of empathy and normative beliefs about aggression, Scand. J. Psychol. 57 pp. 169-176 (2016). doi:10.1111/sjop.12277

15. J.G. Hull, A.M. Draghici, J.D. Sargent, A longitudinal study of risk-glorifying video games and reckless driving., Psychol. Pop. Media Cult. 1 pp. 244-253 (2012). doi: $10.1037 / \mathrm{a} 0029510$

16. R. Ivers, T. Senserrick, S. Boufous, M. Stevenson, H.Y. Chen, M. Woodward, R. Norton, Novice drivers' risky driving behavior, risk perception, and crash risk: Findings from the DRIVE study, Am. J. Public Health. 99 pp. 1638-1644 (2009). doi:10.2105/AJPH.2008.150367

17. http://demografia.stat.gov.pl/bazademografia/Tables.aspx, (n.d.)

18. B.M. Newman, P.R. Newman, Life-Span Development. A Psychological Approach. CENGAGE Learning (2012)

19. J.J. Rolison, Y. Hanoch, S. Wood, P.J. Liu, Risk-taking differences across the adult life span: A question of age and domain, Journals Gerontol. - Ser. B Psychol. Sci. Soc. Sci. 69 pp. 870-880 (2014). doi:10.1093/geronb/gbt081

20. S. Khodarahimi, Sensation-Seeking and Risk-Taking Behaviors: A Study on Young Iranian Adults, Appl. Res. Qual. Life. 10 pp. 721-734 (2015). doi:10.1007/s11482014-9350-2 